\title{
The SNP-Based Profiling of Montecristo Feral Goat Populations Reveals a History of Isolation, Bottlenecks, and the Effects of Management
}

\author{
Elisa Somenzi ${ }^{1, *}$, Gabriele Senczuk $^{2}{ }^{(\mathbb{D}}$, Roberta Ciampolini $\left.{ }^{3}{ }^{(}\right)$, Matteo Cortellari $\left.{ }^{4}{ }^{(}\right)$, Elia Vajana ${ }^{1,5}$, \\ Gwenola Tosser-Klopp ${ }^{6}\left(\mathbb{D}\right.$, Fabio Pilla ${ }^{2}$, Paolo Ajmone-Marsan ${ }^{1,7} \mathbb{1}$, Paola Crepaldi ${ }^{4}\left(\mathbb{D}\right.$ and Licia Colli ${ }^{1,8}$
}

Citation: Somenzi, E.; Senczuk, G.; Ciampolini, R.; Cortellari, M.;

Vajana, E.; Tosser-Klopp, G.; Pilla, F.; Ajmone-Marsan, P.; Crepaldi, P.; Colli, L. The SNP-Based Profiling of Montecristo Feral Goat Populations Reveals a History of Isolation, Bottlenecks, and the Effects of Management. Genes 2022, 13, 213. https://doi.org/10.3390/ genes13020213

Academic Editor: Emilia Bagnicka

Received: 30 December 2021

Accepted: 17 January 2022

Published: 24 January 2022

Publisher's Note: MDPI stays neutral with regard to jurisdictional claims in published maps and institutional affiliations.

Copyright: (C) 2022 by the authors. Licensee MDPI, Basel, Switzerland. This article is an open access article distributed under the terms and conditions of the Creative Commons Attribution (CC BY) license (https:/ / creativecommons.org/licenses/by/ $4.0 /)$.
1 DIANA Dipartimento di Scienze Animali, della Nutrizione e degli Alimenti, Università Cattolica del S. Cuore, 29122 Piacenza, Italy; elia.vajana@epfl.ch (E.V.); paolo.ajmone@unicatt.it (P.A.-M.); licia.colli@unicatt.it (L.C.)

2 Dipartimento di Agricoltura, Ambiente e Alimenti, University of Molise, 86100 Campobasso, Italy; g.senczuk@unimol.it (G.S.); pilla@unimol.it (F.P.)

3 Dipartimento di Scienze Veterinarie, University of Pisa, 56124 Pisa, Italy; roberta.ciampolini@unipi.it

4 Dipartimento di Scienze Agrarie ed Ambientali-Produzione, Territorio, Agroenergia, University of Milano, 20133 Milan, Italy; matteo.cortellari@unimi.it (M.C.); paola.crepaldi@unimi.it (P.C.)

5 Laboratory of Geographic Information Systems (LASIG), School of Architecture, Civil and Environmental Engineering (ENAC), École Polytechnique Fédérale de Lausanne (EPFL), 1015 Lausanne, Switzerland

6 GenPhySE, Université de Toulouse, INRAE, ENVT, F-31326 Castanet-Tolosan, France; gwenola.tosser@inrae.fr

7 Centro di Ricerca Nutrigenomica e Proteomica-PRONUTRIGEN, Università Cattolica del Sacro Cuore, 29122 Piacenza, Italy

8 Centro di Ricerca sulla Biodiversità e sul DNA Antico-BioDNA, Università Cattolica del Sacro Cuore, 29122 Piacenza, Italy

* Correspondence: elisa.somenzi@unicatt.it

\begin{abstract}
The Montecristo wild goat is an endangered feral population that has been on the homonymous island in the Tuscan Archipelago since ancient times. The origins of Montecristo goats are still debated, with authors dating their introduction either back to Neolithic times or between the 6th and 13th century of the Common Era. To investigate the evolutionary history and relationships of this population we assembled a 50K SNP dataset including 55 Mediterranean breeds and two nuclei of Montecristo goats sampled on the island and from an ex situ conservation project. Diversity levels, gene flow, population structure, and genetic relationships were assessed through multiple approaches. The insular population scored the lowest values of both observed and expected heterozygosity, highlighting reduced genetic variation, while the ex situ nucleus highlighted a less severe reduction. Multivariate statistics, network, and population structure analyses clearly separated the insular nucleus from all other breeds, including the population of Montecristo goats from the mainland. Moreover, admixture and gene flow analyses pinpointed possible genetic inputs received by the two Montecristo goat nuclei from different sources, while Runs of Homozygosity (ROHs) indicated an ancient bottleneck/founder effect in the insular population and recent extensive inbreeding in the ex situ one. Overall, our results suggest that Montecristo goats experienced several demographic fluctuations combined with admixture events over time and highlighted a noticeable differentiation between the two nuclei.
\end{abstract}

Keywords: Montecristo feral goats; SNP; nuclear genome; demographic history; Mediterranean Sea; management

\section{Introduction}

For centuries, Mediterranean islands have hosted several feral goat populations, strongly adapted to survive in arid environments and feed scarcity [1]. Among these is the Montecristo feral goat, a free-ranging population inhabiting the homonymous Italian island since ancient times. The Montecristo Island is a relatively small island (ca. 1000 hectares) in 
the Mediterranean basin. Located in the Thyrrenian sea $60 \mathrm{kms}$ from the coasts of Tuscany, this island has been a Nature Reserve since 1971 [2,3], and hosts several endangered and endemic species. The Montecristo feral goats are characterised by phenotypic traits shared both with the domestic goat Capra hircus (i.e., the small size and the wide colour variability) and with the semi-wild goat populations of the Mediterranean basin (i.e., scimitar shape horns, present in both sexes but more prominent in males) [4,5]. Due to the occurrence of mixed phenotypic traits, the taxonomic status of Montecristo feral goats has long been debated, with some authors referring to this population as Capra aegagrus, to point to a closer relationship with the Mediterranean feral goats [6].

Despite several hypotheses having been proposed, the origins of the Montecristo goats are unknown; indeed, any precise inference has been hampered so far by the lack of clear archaeological data owing to the island soil that prevents the formation of fossils [7]. Some authors [8] have suggested that Montecristo goats were introduced onto the island during Neolithic times, while others [9-11] date the first occurrence much more recently between the 6th and 13th centuries, when the goats were exploited as a food resource by the monk community settled on the island. In the mid-19th century the presence of feral goats on the island was reported by Alexandre Dumas in his famous novel "The Count of Montecristo": "At every step that Edmond took he disturbed the lizards glittering with the hues of the emerald; afar off he saw the wild goats bounding from crag to crag", and was further documented by the naturalists exploring the island in the same period [6]. From the late-19th century until the mid-20th Montecristo Island was exploited as a Savoia royal family's game reserve. In the same period, the introduction of goats from the mainland for restocking purposes was reported [12]. Between the 1950s and the 1960s the island was owned by a private company, which established a game reserve [6]. Due to excessive hunting the original nucleus of goats was possibly reduced to less than 10 individuals [10] and subsequently restocked with goats from the mainland [6]. When Montecristo Island was declared a Nature Reserve in 1971 to preserve the autochthonous species and the local goats [2], hunting was finally forbidden, leading to a steady increase in the number of goats, which soon became a threat to the island ecosystem. Since then, several selective culling campaigns have been performed to reduce population size [12].

Currently, a small population of goats are farmed in Tuscany in the province of Grosseto, which are described as the descendants of animals allegedly moved from Montecristo Island to the Italian mainland in the last decades of the 20th century for conservation and research purposes. The information regarding the origin, recent history, and management of these nuclei is scanty, with their establishment being dated back either between the end of the 1970s and 1980s, or even before the Nature Reserve was set up in 1971 [13]. These small nuclei of animals, i.e., each one including one male and four females, were hosted at different breeding facilities on the mainland (Ciampolini R., pers. comm.) and likely underwent strong demographic fluctuations in the following decades.

Starting from the last decade of the 20th century, a few studies have been carried out to characterize Montecristo goats by means of molecular markers. In 1990, Randi and colleagues [13] analysed allozyme loci of 20 samples from the Montecristo goat population, and underlined the occurrence of several introductions of domestic goats from mainland that contributed to the original gene pool. More recently, Doro and colleagues [4] analysed the complete mitochondrial DNA sequence of a single male specimen of Montecristo feral goat, highlighting a similarity with Western European domestic lineages. Analyses of Montecristo goats microsatellites and mtDNA were part of a LIFE project focussed on Montecristo island [14], which highlighted the absence of bottleneck events in the insular population as well as the presence of two unique mitochondrial haplotypes. Furthermore, a clear differentiation between insular and ex situ stocks was assessed [12]. The animals sampled on the mainland, in fact, were not assigned to the gene pool typical of insular Montecristo goats, since they displayed mitochondrial haplotypes and microsatellite alleles not found in the insular population [14]. 
Several authors have discussed the origin and the conservation status of the Montecristo goats during the last decades [6,15]. However, the combined lack of pre-1980s demographical information and extensive genomic sampling has not allowed light to be shed on the genetic heritage of this feral stock, so far.

To tackle this gap, the present work assembled and analysed a 50K SNP dataset including 55 domestic goat breeds and 50 Montecristo individuals, from both the island and the mainland, to investigate the demographical history of the Montecristo population in the context of the Mediterranean basin. To our knowledge, this is the most comprehensive study on the Montecristo feral goat molecular diversity to date, which can represent a first step towards marker-assisted conservation of this peculiar goat population.

\section{Materials and Methods}

\subsection{Dataset Construction and Filtering}

The Montecristo goat samples included 32 individuals (MNT_I) from the free-ranging population inhabiting Montecristo Island sampled between 1995 and 2012, and 18 goats (MNT_M) reared ex situ at a farm in Seggiano on the Mount Amiata (Grosseto province, Tuscany, Italy). The latter population was sampled in 2016 and comprises the descendants of two of the four starting nuclei of individuals allegedly moved from the island of Montecristo to the Italian mainland between the end of the 1970s and the beginning of the 1980s.

The animals were genotyped with the Illumina GoatSNP50 BeadChip [16] as described in Cortellari et al. [17]. Genotypes were merged with publicly available data representing 55 goat breeds from the Mediterranean basin and south-western Asia (Figure 1; Supplementary Table S1) [18-20].

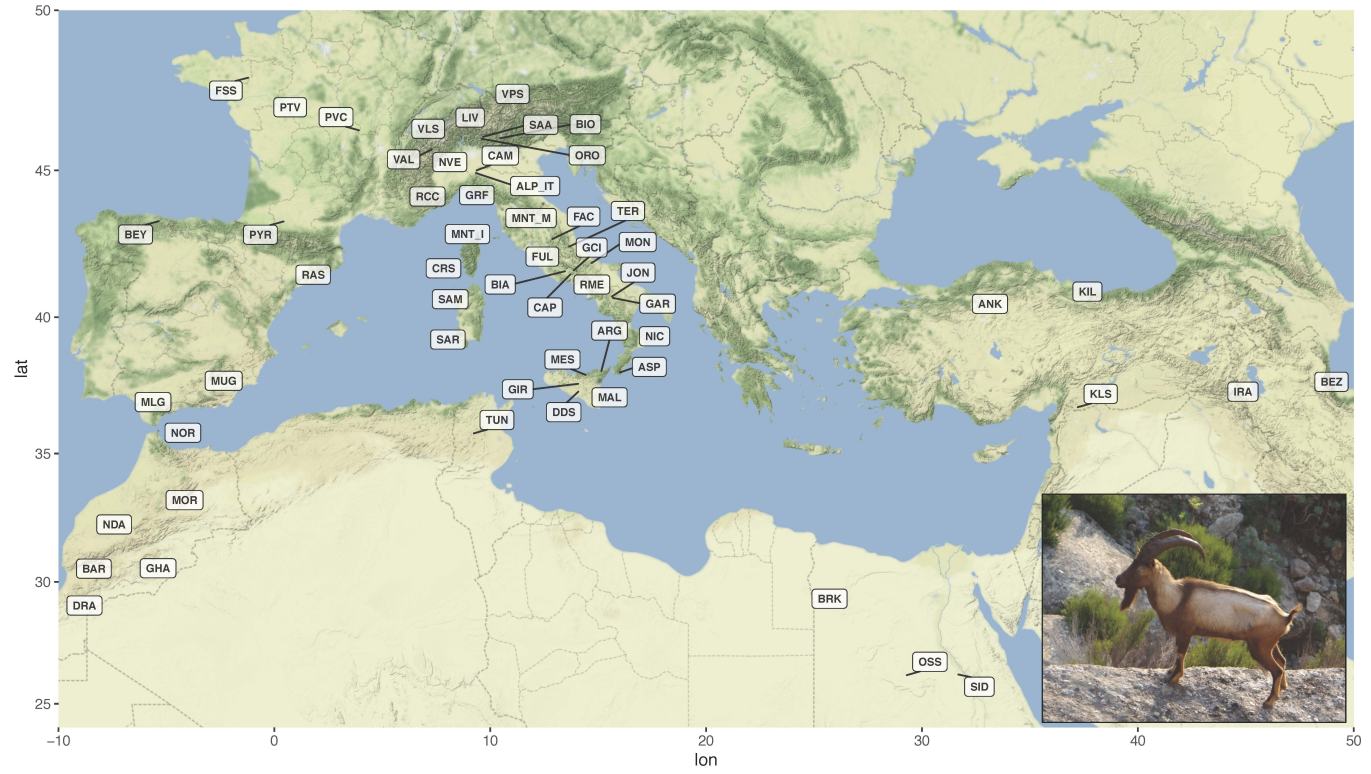

Figure 1. Geographical distribution of the 57 breeds included in the dataset. The labels indicate the centroids of sampling locations. The inset shows a male Montecristo goat with light-coloured phenotype (Photo from https: / / www.ruminantia.it/vi-raccontiamo-le-razze-la-capra-di-montecristo / accessed on 11 November 2021). For the correspondence between labels and breed names refer to Supplementary Table S1.

Data from different sources were re-mapped on the goat reference genome ARS1, merged, and quality-controlled using PLINK 1.9 [20]. Individuals and markers exceeding the following thresholds were removed: (i) SNP call rate < 0.98; (ii) individual genotype call rate $<0.96$; (iii) minor allele frequency (MAF) $<0.1$. SNPs with unknown map position or located on sex chromosomes were removed. Pruning for linkage disequilibrium (LD) was performed using the '-indep-pairwise' function in PLINK [20], where SNPs with $\mathrm{r}^{2}>0.2$ 
were removed from sliding windows of 50 SNPs and a step size of five SNPs. Breeds with sample size larger than 30 individuals were thinned to a subset of 30 representative samples using the function representative.sample implemented in R package BITE [21].

To mitigate the bias possibly deriving from the reduced number of polymorphic loci in MNT_I population, we assembled a second dataset including only the markers scored as polymorphic in MNT_I (poly-MNT_I dataset). The two datasets were subjected to the same analyses and the results were compared.

\subsection{Estimation of Genetic Diversity, Population Structure and Migration Events}

Observed and Expected heterozygosities $\left(\mathrm{H}_{\mathrm{O}}\right.$ and $\left.\mathrm{H}_{\mathrm{E}}\right)$ and the inbreeding coefficient $\left(\mathrm{F}_{\mathrm{IS}}\right)$ values were calculated using the software Arelquin v3.5.2.2, which allows analysing genomic data [22]. To minimize the effects of the different numbers of polymorphic loci on the estimates of diversity, heterozygosity values were corrected over the number of usable SNPs with the formula proposed by Colli and colleagues [23].

Principal Component Analysis (PCA) was performed with the '-pca-clusters' flag in PLINK v1.9 [20] in both and unsupervised (i.e., standard) and a supervised fashion to account for outlier's behaviour, using the '-pca-clusters' function. In this approach, outlier populations are first identified through unsupervised PCA, then principal components are calculated leaving the outlier populations out in the supervised analysis; finally, the individuals belonging to the outlier populations are assigned coordinates and projected onto the supervised PC axes. Results were visualized in R v3.6.1 [24].

Reynolds' unweighted distances between breeds were calculated with Arlequin [22] and used to build a Neighbour-net graph with SplitsTree v4.14.6 software [25]. Admixture $\mathrm{v}$ 1.3.0 [26] was used to evaluate population structure through a maximum-likelihoodbased approach. Analyses were performed for $\mathrm{K}$ values ranging from 2 to 45 . The best fitting $\mathrm{K}$ was identified as the one scoring the lowest cross-validation error value.

The occurrence of migration events was investigated with the software Treemix v. 1.13 [27] by setting windows of 500 consecutive SNPs and testing migration events ( $m$ ) from 0 to 11, with 5 iteration each. An ad hoc statistic implemented in the R package OptM was used to identify the most likely number of migration edges [28]. The robustness of the nodes of Treemix underlying graph was estimated through 100 bootstrap replicates run for the best $m$ value. A consensus tree was produced using the consense.exe executable in PHYLIP v3.695 [29] and plotted with the BITE function treemix.bootstrap [21].

Lastly, we used the LD-based method implemented in the SNeP v1.1 software [30] to evaluate the changes in Effective Population size $(\mathrm{Ne})$ during the last 1000 generations. This analysis was performed on the two Montecristo feral goats' populations MNT_I and MNT_M, and on the three geographically closest breeds, namely, Garfagnana (GRF), Sarda (SAR) and Corse (CRS).

\subsection{Runs of Homozygosity and Heterozygosity-Rich Regions}

Continuous stretches of homozygous sequences, i.e., Runs of homozygosity (ROHs), were scored on the two Montecristo nuclei to assess population demographic history. ROHs were computed with PLINK v1.9 [20] as described in [31]. Number of ROHs per animal, average $\mathrm{ROH}$ length and $\mathrm{ROH}$ distribution across length classes $(0-2 \mathrm{Mb}$, 2-4 Mb, 4-8 Mb, 8-16 Mb, and >16 Mb; see Supplementary Table S2) were calculated. Scored ROHs were visualized chromosome-wise in R v3.6.1 [24] and the ROH coveragederived genomic inbreeding was computed with the dedicated function in $\mathrm{R}$ package detectRUNS [32]. The per-proportion of times each SNP falls inside a run in a given population was calculated using the R package detectRUNS [32]. SNPs with a value in the top $0.1 \%$ of the percentile distribution were considered as statistically significant. Each significant SNP was annotated with the R package GALLO [33], considering an interval of $1000 \mathrm{bp}$ upstream and downstream the examined marker. Genomic inbreeding derived from $\mathrm{ROH}$ coverage was computed for the two Montecristo populations using the dedicated formula implemented in the package detectRUNS [32]. Heterozygosity-rich 
regions (HHRs) were evaluated with the R package detectRUNS through the "Sliding Windows" method with the following criteria: (i) the window size was set to 10 SNPs; (ii) the window threshold was kept with the default 0.05 value; (iii) the minimum number of SNPs in a HHR was 5; and (iv) the minimum length of a HHR was 500 bps. For identifying shared regions of interest, the same approach used for $\mathrm{ROHs}$ was applied. The top $0.1 \%$ SNPs in the percentile distribution of the number of times each SNP falls inside a run were considered as to be significant. Significant markers were annotated with the $R$ package GALLO [33].

\subsection{Approximate Bayesian Computation}

The Approximate Bayesian Computation-Random Forest approach (ABC-RF) implemented in the DiyABC - rf1.0 software [34] was used to test alternative scenarios describing the recent demographic history of Montecristo goats. This approach allows to: (i) simulate multiple historical models; (ii) evaluate the parameter estimated during the analysis; and (iii) rank the best fitting model based on the approximate posterior probabilities.

A dedicated dataset was assembled to carry out ABC-RF analysis, including the two Montecristo populations (MNT_M, MNT_I) together with the geographically and genetically closest breeds as identified in previous analyses: Garfagnana (GRF), Sarda (SAR) and Corse (CRS). To reduce computational burden the dataset was further pruned for LD, reducing the number of SNPs to 9757. To estimate the extent of a possible loss of information in the reduced dataset, we computed the Pearson's correlation coefficient between eigenvector values obtained with the main and the reduced datasets.

To test our hypotheses on recent demographic history, we modelled four different scenarios based on the results of population structure analyses and available historical records on the Montecristo goat population. In Scenario 1 (Supplementary Figure S1, panel a) we tested the hypothesis of the continental population (ancestors of GRF) diverging as first from the insular ones. The Montecristo goat population was modelled as deriving from an admixture event involving the Sarda and Corsa domestic breeds. Under Scenario 2 (Supplementary Figure S1, panel b) we assumed a more ancient origin of the Montecristo goat population, which diverged before the split between the Sarda and Corse breeds. Scenario 3 (Supplementary Figure S1, panel c) was designed to test a different origin of the two Montecristo populations with the insular one originating from the Corse and the mainland one from the Sarda breed. In Scenario 4 (Supplementary Figure S1, panel d) a possible derivation of the Montecristo population from the Corse breed was tested.

\section{Results}

\subsection{Dataset Construction and Filtering}

After quality control routines, a working dataset including 1251 animals and 43,252 SNPs was retained for subsequent analyses; while the number of markers was further reduced to 33,123 SNPs in the poly-MNT_I dataset containing only the markers that were polymorphic in the MNT_I population. The comparison between the results obtained from the main dataset and the poly-MNT_I datasets showed no substantial differences. Therefore, only the results obtained from the main working dataset were shown here.

\subsection{Estimation of Genetic Diversity, Population Structure, and Migration Events}

The Observed heterozygosity $\left(\mathrm{H}_{\mathrm{O}}\right)$ corrected value calculated for the insular Montecristo goats (MNT_I) was the lowest recorded in the dataset (i.e., $\mathrm{H}_{\mathrm{O}}=0.271$ ), and lower than that of the bezoar $\left(\mathrm{H}_{\mathrm{O}}=0.281\right)$ (Supplementary Table S1). The continental population MNT_M, instead, scored a higher value $\left(\mathrm{H}_{\mathrm{O}}=0.324\right)$, which is not far from the lower end of the range of $\mathrm{H}_{\mathrm{O}}$ values scored for the domestic goat breeds $\left(0.348\right.$ (VLS) $<\mathrm{H}_{\mathrm{O}}$ $<0.417$ (MLG). The corrected values of Expected Heterozygosity $\left(\mathrm{H}_{\mathrm{E}}\right)$ were higher than $\mathrm{H}_{\mathrm{O}}$ for both Montecristo populations (MNT_M: $\mathrm{H}_{\mathrm{E}}=0.377$ vs. $\mathrm{H}_{\mathrm{O}}=0.324$ and MNT_I: $\mathrm{H}_{\mathrm{E}}=0.347$ vs. $\mathrm{H}_{\mathrm{O}}=0.281$ ), with the insular population scoring the lowest value in the dataset. For the whole dataset the $p$-values associated to the inbreeding coefficient $\mathrm{F}_{\mathrm{IS}}$ 
estimates were not statistically significant, except for the bezoar $\mathrm{F}_{\mathrm{IS}}=0.233$ (significant at $p<0.005$. Supplementary Table S1).

The first and second Principal Components of the unsupervised PCA together accounted for $5.57 \%$ of the total variance (Figure 2$)$. On PC1 (3.99\% of variance) the breeds were distributed following a seamless north-south geographical pattern, with the northern Italian populations on the left side of the plot and the northern African ones on the right side (Figure 2). The MNT_M population was positioned close to two Spanish breeds, Murciano Granadina (MUG) and Malagueña (MLG).

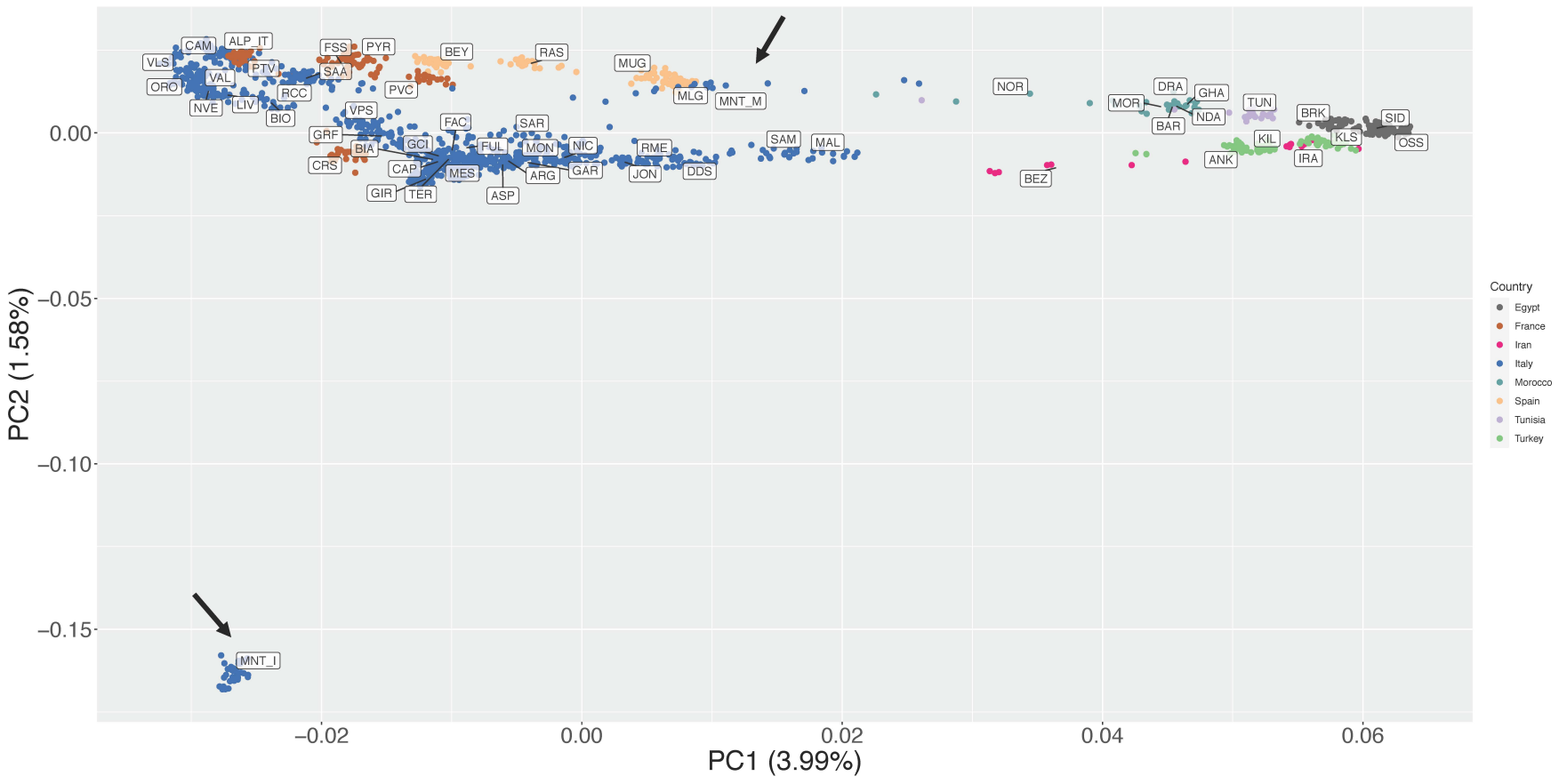

Figure 2. Unsupervised Principal Components Analysis (PC1 vs. PC2). The percentages of variance explained by each component are given into brackets. Arrows indicate position of Montecristo populations in the figure.

The second PC (1.58\% of variance) highlighted an extreme outlier behaviour of the insular Montecristo goats MNT_I, which lies at the bottom left corner of the plot at a great distance from all other populations (Figure 2).

As detailed previously, the supervised Principal Component Analysis (Figure 3; Supplementary Figure S2) was then carried out to minimize the impact of outlier populations. In this analysis, SPC1 (4.1\% of variance) clearly separated the European breeds from the African and south-western Asian ones. Together, SPC1 and SPC2 (5.5\% of variance explained overall) showed a clear clustering of the breeds based on their country of origin and confirmed a north-to-south genetic pattern within Italy, as already highlighted in previous studies [18,19]. The insular Montecristo goat population MNT_I clustered with breeds from central Italy (GRF, FAC, FUL), Sardinia (SAR), and Corse (CRS), while the scatter of points belonging to the ex situ MNT_M individuals was placed close to the origin of the axes and stretched between the SAR and Moroccan populations (Figure 3).

The Neighbour-network based on Reynolds genetic distances (Figure 4) confirmed the geographical structuring of diversity already pointed out by PCA analyses. Both Montecristo goat populations were positioned on long branches, usually interpreted as evidence of prolonged isolation likely combined with genetic drift. Similar to SPCA results, the MNT_I population clustered with the Sarda, Corse, and Garfagnana breeds, while the MNT_M population was with some central Italian (FAC) and Spanish breeds (MLG, MUG, RAS, and BEY). 


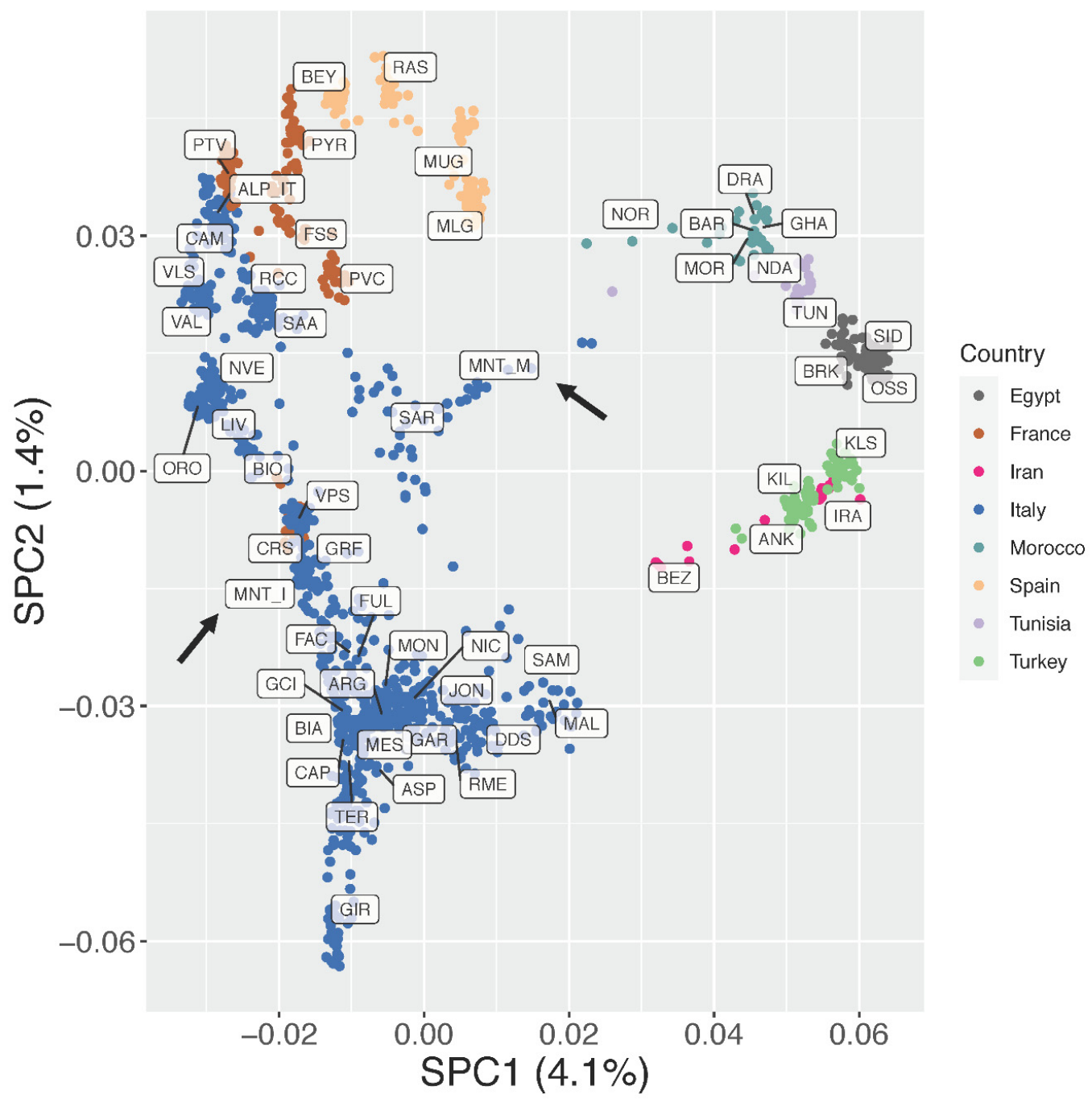

Figure 3. Supervised Principal Component Analysis (SPC1 vs. SPC2). The percentages of variance explained by each component are given into brackets.

Among the tested admixture scenarios ( $\mathrm{K}=2$ to $\mathrm{K}=45$; Figure 5), the best fitting resolution was identified at $\mathrm{K}=31$ according to the CV error decay (Supplementary Figure S3).

The model assuming two ancestral populations $(K=2)$ firstly separated the populations on a geographical basis, with the breeds from European assigned to a cluster different from that of African and south-western Asian ones. Already at this low K, the two Montecristo populations showed different behaviours: MNT_I was clearly assigned to the European cluster, while MNT_M displayed an admixed genomic background including both ancestral components. At $\mathrm{K}=3$ the insular MNT_I population clearly clustered apart from all other breeds. Conversely MNT_M (i) showed the occurrence of a genomic component shared with the breeds from northern Africa, southern France and Spain at $\mathrm{K}=5$; (ii) was assigned to a separated cluster at $\mathrm{K}=6$; and (iii) showed a sub-structure at $\mathrm{K}=30$ (Figure 5).

Regarding the Treemix analysis, the Evanno statistic calculated over five iterations for $m$ from 0 to 10 indicated $m 6$ as the most likely number of gene flow events (Supplementary Figure S4). In the corresponding tree-based graph, most of the nodes were supported by high bootstrap values (Figure 6). Several migration edges connected the northern African breeds with each other and with those from Spain and southern France. MNT_I was positioned on the same branch as CRS, the latter being also connected to the MNT_M basal node by a migration edge. 


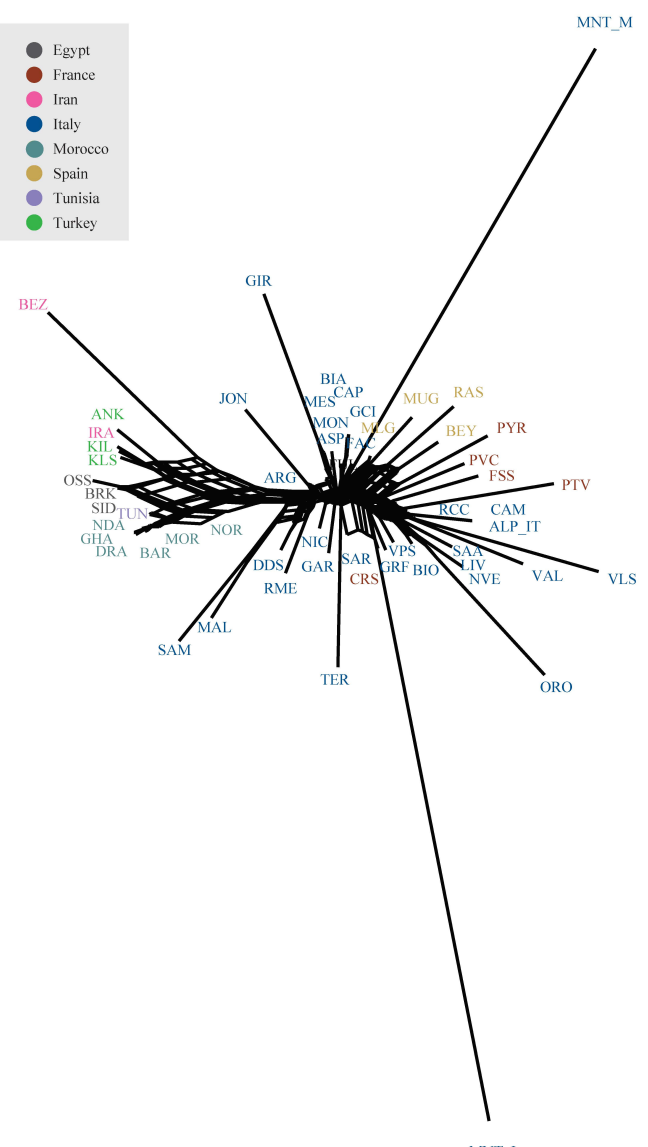

Figure 4. Neighbour-network reconstruction based on Reynolds' genetic distances between breeds.

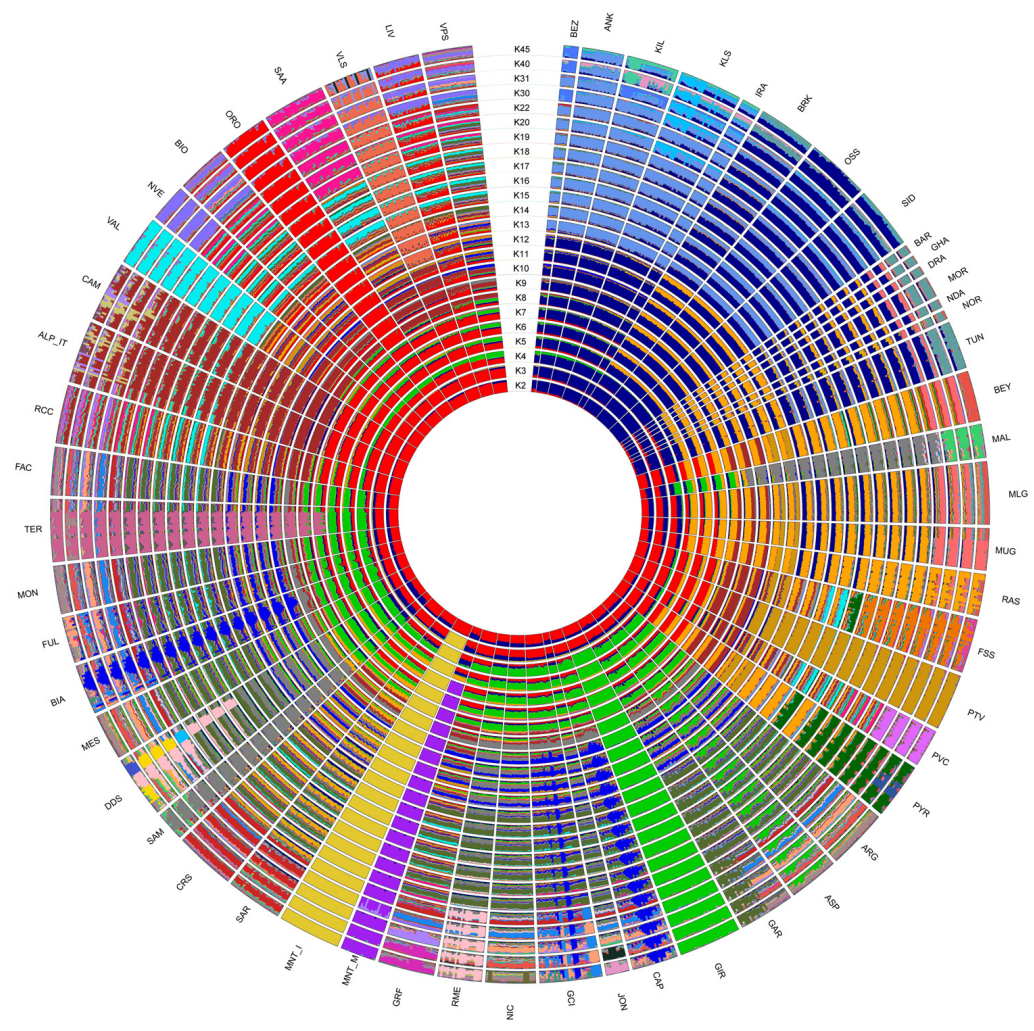

Figure 5. ADMIXTURE software analysis with putative ancestral population (K) computed from 2 to 45. The reconstruction at $K=31$ had the smallest cross-validation error. 


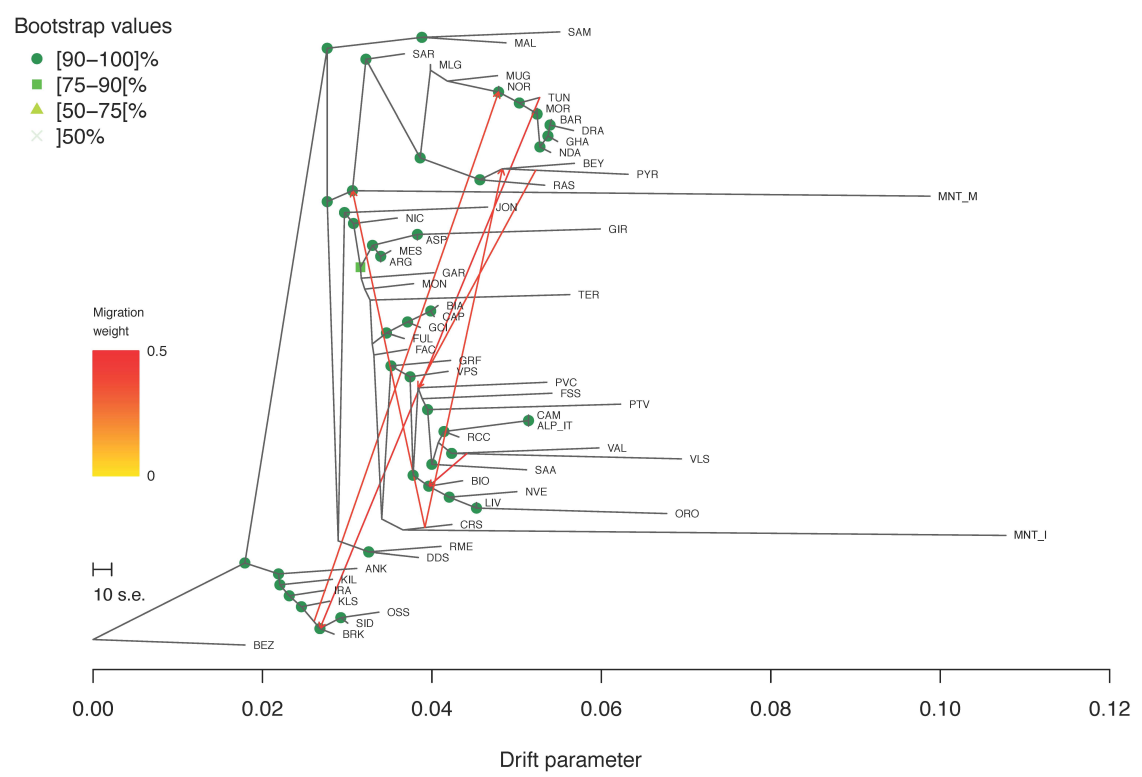

Figure 6. Treemix graph corresponding to $m=6$. Robustness of the nodes was computed over 100 bootstrap replicates.

$\mathrm{SNeP}$ analysis pinpointed a marked but gradual reduction in effective population size over time for both MNT_I and MNT_M. The decline in Ne was consistent among the two Montecristo populations and less steep compared to the behaviour of the domestic SAR, CRS, and GRF (Supplementary Figure S5).

\subsection{Runs of Homozygosity and Heterozygosity-Rich Regions}

The average number of ROHs per animal was 239.7 and 66.35 for MNT_I and MNT_M, respectively, and the total number of ROHs identified was 1128 for the MNT_M and 7191 for the MNT_I population. ROHs of the two populations were classified into five length classes $(0-2 \mathrm{Mb}, 2-4 \mathrm{Mb}, 4-8 \mathrm{Mb}, 8-16 \mathrm{Mb}$, and $>16 \mathrm{Mb}$. Supplementary Table S2): in the MNT_I population, the highest number of $\mathrm{ROHs}$ was scored in the shortest length class $(0-2 \mathrm{Mb})$, with the number of ROHs in the remaining classes gradually decreasing to $71 \mathrm{ROHs}$ in the $>16 \mathrm{Mb}$ class. Conversely, the MNT_M population showed a more homogeneous distribution of $\mathrm{ROHs}$ across the five length classes, with the highest frequency in the 4-8 Mb class (Supplementary Table S2) and with an occurrence of ROHs $>16 \mathrm{Mb}$ class almost as frequent as in the other classes. The values of genomic inbreeding derived from the $\mathrm{ROH}$ coverage were 0.270 for the MNT_M and 0.312 for the MNT_I.

The scored ROHs were plotted chromosome-wise to obtain further insight on the contrasting behaviour of the two Montecristo goat populations, which showed a clear difference in the genomic distribution of the homozygous stretches (Supplementary File S1). The MNT_I individuals, in fact, showed the occurrence of generally short ROHs uniformly distributed along the chromosomes and interspersed with heterozygous stretches, and without major differences between individuals. The MNT_M animals conversely displayed a highly variable behaviour in terms of $\mathrm{ROH}$ occurrence, length, and position. Some individuals showed uninterrupted ROHs spanning over long chromosome tracts, sometimes as long as $>80 \%$ of the chromosome (e.g., see chr 4 ) and accompanied by very extended and completely heterozygous regions (e.g., chr6 and chr19) (Supplementary File S1). Moreover, the single-chromosome plots also pointed at the occurrence of regions consistently homozygous/heterozygous across individuals. This evidence was further investigated by identifying $\mathrm{ROH}$ regions including the top $0.1 \%$ of the most represented SNPs, which were found on chromosomes 1, 2, 3, and 11 for MNT_I, and on chromosome 16 for MNT_M (See Supplementary Table S3). In MNT_I shared ROH islands harboured the genes TNP1, SMARCAL1, MARCHF4, and ST6GALNAC5, while for the MNT_M population the highly shared $\mathrm{ROH}$ region on chromosome 16 included the genes 5S_rRNA, RRP15, KCTD3, 
BRINP3, GPATCH2, ESRRG, TGFB2, and SPATA17. Several unannotated sequences were also found in the ROHs of both populations.

For MNT_I common HRRs were found on chromosomes 6 and 13 (Supplementary Table S3). The HRR on chromosome 6 included the genes PPP3CA, EMCN, CNOT6L, SHLD1, and GPCPD1. HHRs shared by MNT_M individuals were located on chromosomes 1, 2, 8, 13, $14,16,18,22$, and 24 and spanned the genes OTOL1, LYPD6B, NFIB, BMP1, OPTN, BEND7, MCM10, PHYH, ASAP1, ADCY8, TATDN3, RPS6KC1, ANGEL2, NSL1, LOXHD1, KATNAL2, ST8SIA5, PIAS2, SKOR2, and SMAD4.

\subsection{Approximate Bayesian Computation}

According to the value of the Pearson correlation coefficient calculated between the main vs. reduced dataset PCA loadings (0.971), loss of information due to the reduction in the number of SNPs was excluded. Scenario 2 (divergence of the Montecristo goat population before the split between the Sarda and Corse breed) resulted in the most supported one (64.8\% of the votes in model choice prediction). However, the simulations never fit the observed data (Supplementary Figure S7), which suggests that none of the four models devised could thoroughly account for the complex demographic history of the Montecristo goats.

\section{Discussion}

In this study, we performed the first genome wide assessment of the genetic variation in Montecristo feral goats to shed light on their levels of polymorphism, population structure, and demographic history, and to evaluate their historic relationships with goat breeds across the Mediterranean area.

Previous investigations on the origin of Montecristo feral goats were based either on phenotypic traits, or on a limited number of allozymic/microsatellite loci or on partial fragments of the mtDNA control region $[4,14,16]$. Here, the availability of new genotype data from two different nuclei of Montecristo goats, i.e., the free-ranging insular population and the captive-bred nucleus, also enabled us to compare their genomic make-up and to evaluate the effectiveness of the ex situ conservation project that has been carried out on the Italian mainland since the last decades of the 20th century. Overall, the results consistently highlighted marked molecular differences between the in situ and ex situ nuclei. The in situ population showed the lowest recorded value of observed heterozygosity in the dataset (Supplementary Table S1), a strong outlier behaviour in the unsupervised PCA (Figure 2), a clear independent clustering in admixture analysis (Figure 5), and a high value of genomic inbreeding $\left(\mathrm{F}_{\mathrm{ROH}}=0.312\right)$. These findings are in line with expectations, considering the geographical isolation and the repeated bottleneck events that have characterised the demographic history of the insular population, at least from the 18th century. They also agree with previous studies on insular populations, i.e., goats from the Mediterranean basin [35] and Soay sheep from the Scottish island of Hirta [36,37]. In all cases, insular populations had increased levels of inbreeding and a reduced variability compared to the nearby mainland populations. $\mathrm{ROH}$ analysis identified a high frequency of short $\mathrm{ROHs}$ that can be traced back to ancient bottlenecks and founder effects (Supplementary Table S2). Moreover, in the supervised PCA (Figure 3), Neighbour-network (Figure 4), and Treemix graph (Figure 6), the insular MNT_I population showed a genetic proximity to local breeds from Central Italy and the nearby islands of Corse and Sardinia, as expected based on the geographical location of Montecristo Island in the Tuscan archipelago, and the recorded inputs of domestic stocks during the 20th century.

Taken together, the results obtained from the insular population account for an ancestral genomic background shared with domestic breeds of the Thyrrenian sea area, subsequently moulded by a history of prolonged isolation, with several ancient bottlenecks likely accompanied by gene flow events from domestic stocks mainly from neighbouring areas.

Conversely, the population from the mainland displayed higher observed heterozygosity $\left(\mathrm{MNT} \_\mathrm{M} \mathrm{H}_{\mathrm{O}}=0.325\right)$ and lower genomic inbreeding $\left(\mathrm{F}_{\mathrm{ROH}}=0.270\right)$ compared to 
the insular population (MNT_I H $\left.\mathrm{H}_{\mathrm{O}}=0.272 ; \mathrm{F}_{\mathrm{ROH}}=0.312\right)$. The inbreeding level of the mainland population is remarkably higher than in domestic goat breeds from Italy [38] and other areas of the world $[39,40]$, while observed heterozygosity is only slightly lower than those observed in other breeds.

This is the result of the peculiar demographic history of the ex situ population. Four original ex situ nuclei were established, each one including only one male and four females, which inevitably contributed to a reduced amount of starting genetic variation. The nuclei were hosted at different farms and bred separately, without exchange of males and females for several generations (Ciampolini R., per. comm.). This led to a fast increase in inbreeding due to prolonged reproductive isolation, as testified by the extensive occurrence of long Runs of Homozygosity.

A few years ago, the only two remaining nuclei were finally merged into a single population (Ciampolini R., per. comm.). This recent merging is the likely cause of the higherthan-expected $\mathrm{H}_{\mathrm{O}}$ in the mainland population, as an increase in observed heterozygosity is expected to occur following the removal of a reproductive barrier between two formerly separated populations, particularly when they are highly inbred and heavily affected by genetic drift due to small number of founders and small population size. This is further confirmed by the occurrence of long stretches of completely heterozygous regions (Supplementary File S1).

The peculiar genomic makeup of the ex situ population, characterised by a mosaic of alternated long stretches of completely homozygous/heterozygous regions in most of the individuals (Supplementary File S1), likely affected the behaviour of MNT_M in several analyses, making the identification of the actual relationship with the insular population and the other breeds difficult. The PCA/sPCA, population structure and neighbour-network results (Figures 2, 4 and 5), in fact, pointed to an affinity between the ex situ nucleus and the Italian Sarda, the Spanish and northern African breeds. This evidence is not consistent with the behaviour of MNT_I in the same analyses, nor with the known history of MNT_M after the establishment of the ex situ nuclei, even if the possible occurrence of unrecorded crossbreeding events with other domestic goats (e.g., Sarda or central Italian breeds) cannot be ruled out.

The more supported scenario obtained from the ABC analyses accounted for a first separation of the central Italian Garfagnana (GRF), followed by that of the Montecristo populations, and later by that of the Sarda (SAR) and Corse (CRS) breeds. This scenario would suggest a shared ancestry between the two MNT populations and their common, but more ancient, origin with the Sardo-Corse domestic stocks. However, these results are to be taken with caution, as simulated data did not fit the observed ones (Supplementary Figure S6), possibly because of the MNT_M peculiar genetic makeup. Overall, current results are not conclusive on the relationships between the two Montecristo goat populations and further analyses are needed, possibly based on whole genome sequence and the analysis of haplotype blocks.

Conversely, some interesting genes were mapped in the most shared $\mathrm{ROH} / \mathrm{HRR}$ regions. In MNT_I, the most shared ROHs harboured, among others, the genes TNP1 and SMARCAL1, respectively associated to spermiogenesis [41] and genome integrity [42] (Supplementary Table S3). The highly shared HRR on chr6, instead, harboured the gene PPP3CA, previously associated to fecundity traits and litter size in small ruminants $[43,44]$, while the gene GPCPD1 found in chr13 HRR was identified as playing a potential role in the metabolism of lipids and the lipoprotein pathway in sheep [45]. These results may suggest that both the fixation of specific variants in genes related to reproduction and integrity of the genome on the one hand, and the maintenance of consistent heterozygosity of genes involved in fecundity and energy metabolism on the other hand, may have played a role in the adaptation to the harsh environment of the island despite recurrent demographic fluctuations.

Conversely, molecular evidence points to a fixation of variants in genes involved in disease resistance, which may be alarming, and to the retention of heterozygosity in genes 
related to the development of internal organs and fertility in the case of the Montecristo goat population from the mainland.

\section{Conclusions}

In this study, we present the first comprehensive analysis of the demographic history and genome-wide molecular variation in Montecristo feral goats. According to our results, the insular population faced several demographic fluctuations over the centuries, which partially eroded the original genomic make-up in combination with gene flow events from other goat breeds. This population shares its ancestry with breeds from the surrounding areas of Sardinia, Corse, and Tuscany and does not carry signatures of recent inbreeding. Conversely, the molecular diversity of the mainland Montecristo goat population seems to have been severely impacted by the dynamics of the ex situ breeding that confounds the reconstruction of past population history. Overall, our findings represent a starting point for the implementation of marker-assisted monitoring and conservation plans to preserve the genomic heritage of the feral goats from Montecristo Island.

Supplementary Materials: The following supporting information can be downloaded at: https: / / www.mdpi.com/article/10.3390/genes13020213/s1, Supplementary Table S1: Breed code, breed name, country of origin, source dataset (AdaptMap [19]; IGC2 [17]), number of individuals pre-QC (Raw dataset)), number of individuals in the working dataset (WD), observed heterozygosity $\left(\mathrm{H}_{\mathrm{O}}\right)$, expected heterozygosity $\left(\mathrm{H}_{\mathrm{E}}\right)$ values corrected over the number of usable loci, inbreeding coefficient $\left(\mathrm{F}_{\mathrm{IS}}\right)$. Statistical significance as follows: ${ }^{* * *}=p<0.005$. Supplementary Table S2: Summary of the number of $\mathrm{ROH}$ segments for different length categories scored in the two Montecristo goat nuclei. Supplementary table S3: Table summarising the $0.1 \%$ most shared regions of Runs of Homozygosity (ROH) and Heterozygosity Rich Regions (HRR) identified in the two Montecristo populations with the genes included. Supplementary Figure S1: Schematic representation of: (a) Scenario 1; (b) Scenario 2; (c) Scenario 3; and (d) Scenario 4 of ABC-RF analysis. Populations are coded as follow: pop 1: CRS; pop 2: GRF; pop 3: MNT_M; pop 4: MNT_I; pop 5: SAR. Supplementary Figure S2: Supervised Principal Component Analysis (SPC1 vs. SPC2). The percentages of variance explained by each component are given into brackets. Supplementary Figure S3: Cross-Validation CV error values calculated for Admixture K values 2-45. Supplementary Figure S4: (a) The mean and standard deviation (SD) calculated across 5 iterations for the composite likelihood $\mathrm{L}(\mathrm{m})$ (left axis, black circles) and proportion of variance explained (right axis, red circles). (b) The second-order rate of change $(\mathrm{Dm})$ across values of $\mathrm{m}$. Supplementary Figure S6: Projection of the datasets from the training set on the first two linear discriminant analysis (LDA) axes. The location of the observed dataset in the LDA projection is indicated by the red dot. Supplementary File S1: ROHs of the two Montecristo populations plotted chromosome-wise.

Author Contributions: Conceptualization, E.S., M.C., G.S., F.P., P.A.-M., P.C. and L.C.; methodology, E.S., G.S., M.C., P.C. and L.C.; software, E.S., E.V., G.S. and M.C.; validation, E.S., M.C., G.S., P.A.-M., P.C. and L.C.; formal analysis, E.S., G.S., M.C. and L.C.; investigation, E.S., E.V., G.S., M.C., P.C. and L.C.; resources, R.C., G.T.-K., F.P., P.A.-M., P.C. and L.C.; data curation, E.S., E.V., M.C. and G.S.; writing—original draft preparation, E.S., M.C., G.S., P.A.-M., P.C. and L.C.; writing-review and editing, E.S., E.V., G.S., R.C., G.T.-K., F.P., P.A.-M., P.C. and L.C.; visualization, E.S. and L.C.; supervision, P.C. and L.C.; project administration, L.C.; funding acquisition, G.T.-K., P.C. and L.C. All authors have read and agreed to the published version of the manuscript.

Funding: Financial support to the publication of this manuscript was provided by the Linea D.3.1 (years 2018 and 2019) of the Università Cattolica del S. Cuore within its activities of promotion and dissemination of scientific research.

Institutional Review Board Statement: Ethical review and approval were waived for this study, due to the usage of genotype data available from the research studies by Cortellari et al. $2021 \mathrm{https}$ : / / doi.org/10.1038/s41598-021-89900-2 (accessed on 27 November 2021) and Cortellari et al. 2021 https:/ / doi.org/10.1186/s12711-021-00685-4 (accessed on 27 November 2021) previously approved by the Ethical committee of the Department of Veterinary Science of the University of Messina (code 046/2020).

Informed Consent Statement: Not applicable. 
Data Availability Statement: The genotyping data used in this study are deposited and publicly available on Mendeley Data (DOI: 10.17632/hnd59×6gmg.1; URL: https:// data.mendeley.com/ datasets/hnd59 $\ \backslash$ times\$6gmg/1 accessed on 11 December 2021) and on DRYAD (URL: https:/ / datadryad.org/stash/dataset/doi:10.5061/dryad.v8g21pt accessed on 11 December 2021).

Acknowledgments: The authors wish to thank ISPRA Istituto superiore per la protezione e la ricerca ambientale (Ozzano Emilia, BO, Italy) and particularly Ettore Randi for providing Montecristo Island goat samples and genotypes, and all the researchers involved in the Italian Goat Consortium and the Italian National Breeders Association of Sheep and Goat (Asso.Na.Pa).

Conflicts of Interest: The authors declare no conflict of interest.

\section{References}

1. Horwitz, L.K.; Bar-Gal, G.K. The Origin and Genetic Status of Insular Caprines in the Eastern Mediterranean: A Case Study of Free-Ranging Goats (Capra aegagrus cretica) on Crete. Hum. Evol. 2006, 21, 123-138. [CrossRef]

2. Pavan, M. Montecristo riserva naturale. Ist. Entomol. Agrar. Pavia/Tipografia Meroni Albese (Como) 1971, 36. Available online: http:/ / www.pngp.it/sites/default/files/libri_20170915.pdf (accessed on 30 December 2021).

3. European Committee for the Conservation of Nature and Natural Resources. Montecristo Island Nature Reserve-Application for the European Diploma. 1986. Available online: https:/ / rm.coe.int/group-of-specialists-on-protected-areas-montecristoisland-nature-rese/16808aa975 (accessed on 30 December 2021).

4. Doro, M.G.; Casu, G.; Leoni, G.G.; Naitana, S.; Pirastu, M.; Novelletto, A.; Fraticelli, F. The complete mitochondrial DNA sequence of the Montecristo goat. Livest. Sci. 2016, 188, 120-123. [CrossRef]

5. Ciani, F.; Masseti, M. Considerazioni sull'origine della popolazione ircina dell'isola di Montecristo, nel Mar Tirreno settentrionale. Elementi per un confronto cronologico-culturale con l'antica diffusione artificiale dell'egagro (Capra aegagrus Erxleben, 1777) nelle isole del. Atti Conv. Genet. Conserv. fauna Suppl. Ric. Biol. Selvag. 1991, 18, 123-133.

6. Masseti, M. The wild goat, Capra aegagrus Erxleben, 1777, of the island of Montecristo (Northern Tyrrhenian Sea, Italy): Does it still exist? Mammalia 2016, 80, 125-141. [CrossRef]

7. Boitani, L.; Lovari, S.; Vigna Taglianti, A. Mammalia III. Carnivora, artiodactyla. Edagricole-New Business Media. 2003. Available online: https:/ / www.ibs.it/mammalia-iii-carnivora-artiodactyla-libro-vari/e/9788850648795 (accessed on 30 December 2021).

8. Masseti, M. The wild goats Capra aegagrus Erxleben, 1777 of the Mediterranean Sea and the Eastern Atlantic Ocean islands. Mamm. Rev. 2009, 39, 141-157. [CrossRef]

9. Bruno, S.; Sauli, G. Montecristo. Nat. E Mont. 1976, 23, 7-27.

10. Angelici, F.M.; Laurenti, A.; Nappi, A. A checklist of the mammals of small Italian islands. Hystrix Ital. J. Mammal. 2009, 20 , 3-27.

11. Toschi, A. Note sui vertebrati dell'isola di Montecristo. Compositori 1953.

12. Raganella, E.P.; Lazzaro, L.; Gotti, C.; Baccetti, N. Piano di Gestione e Conservazione Della Capra di Montecristo: Sintesi del Contesto e Azioni. 2015. Available online: https://www.restoconlife.eu/wordpress/wp-content/uploads/2015/06/Piano-digestione-della-capra-di-Montecristo.pdf (accessed on 30 December 2021).

13. Preserving the Biodiversity of the 'Il Felcetone' Farm in Tuscany. Available online: https://www.nandoandelsaperettifoundation. org/en/page.php/page.php?project=512 (accessed on 30 December 2021).

14. Zanichelli, F.; Giannini, F.; de Pietro, F.; Puppo, F. I Quaderni del Parco, documenti tecnici volume 2 PROGETTO LIFE+ MONTECRISTO 2010, Eradicazione di Componenti Florofaunistiche Aliene Invasive e Tutela di Specie e Habitat Nell'arcipelago Toscano. 2014. Available online: https://www.mite.gov.it/sites/default/files/archivio/allegati/life/life_pubblicazione_montecristo2 010.pdf (accessed on 30 December 2021).

15. Gippoliti, S. The wild goat of Montecristo Island: Did it ever exist? Mammalia 2016, 80, 221-222. [CrossRef]

16. Tosser-Klopp, G.; Bardou, P.; Bouchez, O.; Cabau, C.; Crooijmans, R.; Dong, Y.; Donnadieu-Tonon, C.; Eggen, A.; Heuven, H.C.M.; Jamli, S.; et al. Design and characterization of a 52K SNP chip for goats. PLoS ONE 2014, 9, e86227. [CrossRef] [PubMed]

17. Cortellari, M.; Barbato, M.; Talenti, A.; Bionda, A.; Carta, A.; Ciampolini, R.; Ciani, E.; Crisà, A.; Frattini, S.; Lasagna, E.; et al. The climatic and genetic heritage of Italian goat breeds with genomic SNP data. Sci. Rep. 2021, 11, 10986. [CrossRef] [PubMed]

18. Nicoloso, L.; The Italian Goat Consortium; Bomba, L.; Colli, L.; Negrini, R.; Milanesi, M.; Mazza, R.; Sechi, T.; Frattini, S.; Talenti, A.; et al. Genetic diversity of Italian goat breeds assessed with a medium-density SNP chip. Genet. Sel. Evol. 2015, 47, 62. [CrossRef]

19. Stella, A.; The AdaptMap Consortium; Nicolazzi, E.L.; Van Tassell, C.P.; Rothschild, M.F.; Colli, L.; Rosen, B.D.; Sonstegard, T.S.; Crepaldi, P.; Tosser-Klopp, G.; et al. AdaptMap: Exploring goat diversity and adaptation. Genet. Sel. Evol. 2018, 50, 61. [CrossRef] [PubMed]

20. Chang, C.C.; Chow, C.C.; Tellier, L.C.; Vattikuti, S.; Purcell, S.M.; Lee, J.J. Second-generation PLINK: Rising to the challenge of larger and richer datasets. Gigascience 2015, 4, 7. [CrossRef]

21. Milanesi, M.; Capomaccio, S.; Vajana, E.; Bomba, L.; Garcia, J.F.; Ajmone-Marsan, P.; Colli, L. BITE: An R package for biodiversity analyses. bioRxiv 2017. [CrossRef]

22. Excoffier, L.; Lischer, H.E.L. Arlequin suite ver 3.5: A new series of programs to perform population genetics analyses under Linux and Windows. Mol. Ecol. Resour. 2010, 10, 564-567. [CrossRef] 
23. Colli, L.; The AdaptMap Consortium; Milanesi, M.; Talenti, A.; Bertolini, F.; Chen, M.; Crisà, A.; Daly, K.G.; Del Corvo, M.; Guldbrandtsen, B.; et al. Genome-wide SNP profiling of worldwide goat populations reveals strong partitioning of diversity and highlights post-domestication migration routes. Genet. Sel. Evol. 2018, 50, 58. [CrossRef]

24. R Core Team. R: A Language and Environment for Statistical Computing. 2017. Available online: http:/ / r.meteo.uni.wroc.pl/ web/packages/dplR/vignettes/intro-dplR.pdf (accessed on 30 December 2021).

25. Huson, D.H.; Bryant, D. Application of phylogenetic networks in evolutionary studies. Mol. Biol. Evol. 2006, 23, 254-267. [CrossRef]

26. Alexander, D.H.; Novembre, J.; Lange, K. Fast model-based estimation of ancestry in unrelated individuals. Genome Res. 2009, 19, 1655-1664. [CrossRef]

27. Pickrell, J.K.; Pritchard, J.K. Inference of Population Splits and Mixtures from Genome-Wide Allele Frequency Data. PLoS Genet. 2012, 8, 1655-1664. [CrossRef] [PubMed]

28. Fitak, R.R. OptM: An R package to optimize the number of migration edges using threshold models. J. Hered. 2018.

29. Felsenstein, J. PHYLIP (Phylogeny Inference Package) Version 3.6. Distributed by the Author. 2004. Available online: http: / / www.evolution.gs.washington.edu/phylip.html (accessed on 30 December 2021).

30. Barbato, M.; Orozco-terWengel, P.; Tapio, M.; Bruford, M.W. SNeP: A tool to estimate trends in recent effective population size trajectories using genome-wide SNP data. Front. Genet. 2015, 6, 109. [CrossRef] [PubMed]

31. Cortellari, M.; Bionda, A.; Negro, A.; Frattini, S.; Mastrangelo, S.; Somenzi, E.; Lasagna, E.; Sarti, F.M.; Ciani, E.; Ciampolini, R.; et al. Runs of homozygosity in the Italian goat breeds: Impact of management practices in low-input systems. Genet. Sel. Evol. 2021, 53, 92. [CrossRef] [PubMed]

32. Biscarini, F.; Cozzi, P.; Gaspa, G.; Marras, G. detectRUNS: An R package to detect runs of homozygosity and heterozygosity in diploid genomes. CRAN 2019, 8, 2019.

33. Fonseca, P.A.S.; Suárez-Vega, A.; Marras, G.; Cánovas, Á. GALLO: An R package for genomic annotation and integration of multiple data sources in livestock for positional candidate loci. Gigascience 2020, 9, giaa149. [CrossRef] [PubMed]

34. Collin, F.; Durif, G.; Raynal, L.; Lombaert, E.; Gautier, M.; Vitalis, R.; Marin, J.; Estoup, A. Extending approximate Bayesian computation with supervised machine learning to infer demographic history from genetic polymorphisms using DIYABC Random Forest. Mol. Ecol. Resour. 2021, 21, 2598-2613. [CrossRef]

35. Cardoso, T.F.; The AdaptMap Consortium; Amills, M.; Bertolini, F.; Rothschild, M.; Marras, G.; Boink, G.; Jordana, J.; Capote, J.; Carolan, S.; et al. Patterns of homozygosity in insular and continental goat breeds. Genet. Sel. Evol. 2018, 50, 56. [CrossRef]

36. McHugo, G.P.; Browett, S.; Randhawa, I.; Howard, D.J.; Mullen, M.P.; Richardson, I.W.; Park, S.D.E.; Magee, D.A.; Scraggs, E.; Dover, M.J.; et al. A Population Genomics Analysis of the Native Irish Galway Sheep Breed. Front. Genet. 2019, 10, 1-13. [CrossRef]

37. Selli, A.; Ventura, R.V.; Fonseca, P.A.S.; Buzanskas, M.E.; Andrietta, L.T.; Balieiro, J.C.C.; Brito, L.F. Detection and Visualization of Heterozygosity-Rich Regions and Runs of Homozygosity in Worldwide Sheep Populations. Animals 2021, 11, 2696. [CrossRef]

38. Mastrangelo, S.; Di Gerlando, R.; Sardina, M.; Sutera, A.; Moscarelli, A.; Tolone, M.; Cortellari, M.; Marletta, D.; Crepaldi, P.; Portolano, B. Genome-wide patterns of homozygosity reveal the conservation status in five italian goat populations. Animals 2021, 11, 1510. [CrossRef] [PubMed]

39. Nandolo, W.; Mészáros, G.; Banda, L.J.; Gondwe, T.N.; Lamuno, D.; Mulindwa, H.A.; Nakimbugwe, H.N.; Wurzinger, M.; Utsunomiya, Y.T.; Woodward-Greene, M.; et al. Timing and extent of inbreeding in African goats. Front. Genet. 2019, 10, 537. [CrossRef] [PubMed]

40. Burren, A.; Neuditschko, M.; Signer-Hasler, H.; Frischknecht, M.; Reber, I.; Menzi, F.; Drögemüller, C.; Flury, C. Genetic diversity analyses reveal first insights into breed-specific selection signatures within Swiss goat breeds. Anim. Genet. 2016, 47, 727-739. [CrossRef] [PubMed]

41. Miyagawa, Y.; Nishimura, H.; Tsujimura, A.; Matsuoka, Y.; Matsumiya, K.; Okuyama, A.; Nishimune, Y.; Tanaka, H. Singlenucleotide polymorphisms and mutation analyses of the TNP1 and TNP2 genes of fertile and infertile human male populations. J. Androl. 2005, 26, 779-786. [CrossRef]

42. Bansbach, C.E.; Bétous, R.; Lovejoy, C.A.; Glick, G.G.; Cortez, D. The annealing helicase SMARCAL1 maintains genome integrity at stalled replication forks. Genes Dev. 2009, 23, 2405-2414. [CrossRef]

43. Islam, R.; Liu, X.; Gebreselassie, G.; Abied, A.; Ma, Q.; Ma, Y. Genome-wide association analysis reveals the genetic locus for high reproduction trait in Chinese Arbas Cashmere goat. Genes Genom. 2020, 42, 893-899. [CrossRef]

44. E, G.-X.; Zhao, Y.-J.; Huang, Y.-F. Huang, Selection signatures of litter size in Dazu black goats based on a whole genome sequencing mixed pools strategy. Mol. Biol. Rep. 2019, 46, 5517-5523. [CrossRef]

45. Yang, J.; Li, W.-R.; Lv, F.-H.; He, S.-G.; Tian, S.; Peng, W.-F.; Sun, Y.-W.; Zhao, Y.-X.; Tu, X.-L.; Zhang, M.; et al. Whole-Genome Sequencing of Native Sheep Provides Insights into Rapid Adaptations to Extreme Environments. Mol. Biol. Evol. 2016, 33, 2576-2592. [CrossRef] 